Wicaksono, Rachel ORCID:

https://orcid.org/0000-0003-0312-8491 (2020) Native and nonnative speakers of English in TESOL. In: Ontologies of English: Conceptualising the language for learning, teaching and assessment. Cambridge Applied Linguistics . Cambridge, Cambridge University Press

Downloaded from: http://ray.yorksj.ac.uk/id/eprint/4651/

The version presented here may differ from the published version or version of record. If you intend to cite from the work you are advised to consult the publisher's version:

Research at York St John (RaY) is an institutional repository. It supports the principles of open access by making the research outputs of the University available in digital form. Copyright of the items stored in RaY reside with the authors and/or other copyright owners. Users may access full text items free of charge, and may download a copy for private study or non-commercial research. For further reuse terms, see licence terms governing individual outputs. Institutional Repository Policy Statement

\title{
RaY
}

Research at the University of York St John

For more information please contact RaY at ray@yorks.ac.uk 


\section{Native and non-native speakers of English in TESOL}

Rachel Wicaksono, York St John University

\section{Introduction}

This chapter explores ideas about '(non-)native' speakers of English, with particular reference to the professional context of teaching English to speakers of other languages (TESOL). The use of '(non-)native' speaker to describe a person's use of English remains common in a variety of domains, despite much scholarly and professional argument against the term. Given that learners and teachers comprise the educational context of this chapter, I have chosen to focus on the native and non-native speakers themselves, rather than on their (so-called) native and non-native uses of English. In doing so, I hope not to fall in to the trap of thinking of people as permanent members of closed categories, but, on the contrary, show how we might raise awareness of the (potentially negative) effects of such thinking on speakers of English, in the TESOL profession.

In the first section of the chapter, I consider how 'native' has been used to describe speakers of English: in popular discourse, by TESOL scholars, and in teacher recruitment. Next, I explore contestations of the native speaker idea and add to these, using work on ontologies of English (see Hall, this volume), language cognition, English as a lingua franca, and identities. Finally, I suggest what might be done to re-frame, alleviate, or resist some of the negative effects of the native speaker idea on (individuals associated with) the TESOL profession.

2 The use of the native speaker idea...

\section{1 ...in popular discourse}

The idea of a 'native speaker' continues to circulate widely in popular discourse. Aside from multiple dictionary definitions and online encyclopaedia entries, an internet search shows many examples of the phrase: on news websites, for example, "The message, written in English, was sent by a native speaker" (Morrison, 2016); in a UK government report, "This research relates to the presence of native speakers in A level modern foreign languages" (Taylor and Zanini, 2017); and on recruitment websites, for example, "searching for native speakers of British English" (Rosetta Stone, n.d). At the time of writing this chapter, it is probably fair to say that the phrase 'native speaker' is regarded as entirely unproblematic by most users of English.

These uses of 'native speaker' in popular discourse are attached to other ideas about English. The first two examples in the previous paragraph seem to imply an (inevitably high) level of competence in the use of English-'competence' is a concept I return to in section 3.2 below. The third example implies competence and the importance of place: the combined, and common, assumption that people born in certain parts of the world (in this example, the United Kingdom) (all) speak the best English. This brings us to the next section, in which I give more examples of such place-based definitions. 
Often, a place-based definition of 'native speaker' uses countries and nationalities to delimit the members of the category, and there are examples of this use in scholarly work on TESOL. Medgyes (1992, p. 340), for example, in answer to the question 'who is a native speaker?' says, "A Briton is. A Hungarian is not. An Australian is. A French national is not". Such definitions may acknowledge the use of English in places where there is a history of the use of English, such as India, and of intervening variables such as education, age, migration and home language. Place-based definitions may also allow for less competent 'native' users of English, such as this early example in a fifteenth century poem, published by William Caxton, as follows, "And I conuersaunte and borne in the partes, where my natyf langage is moost corrupt [trans: And I am familiar with, and was born in, the region where my native language is very unsound/spoiled]" (Harvey, 1984). Despite these types of allowances, using the 'all other things being equal' argument, proponents of place-based definitions argue that a non-native speaker can never achieve the level of competence of a native speaker, because they were, or are, in the wrong place.

Place-based definitions of 'native speaker' conflate a nation-based identity with language use. Political borders are assumed to map directly onto borders between languages and language is considered to be a defining characteristic of national identity. This is part of what Hall (this volume) calls "Englishry": the use of 'English' to mean a practice or product of 'the English'. More specifically, this use of 'English' implies that being a native speaker of English is an essential component of English identity. As Hall points out, this conflation incorrectly assumes that the 'national language' has clear dividing lines between English and not-English, and that these lines are the same as the borders between countries.

Scholarly work that aims to correct discrimination against non-native speaker teachers in the TESOL profession (for more on this discrimination, see section 2.4 below) may have had the effect of unintentionally reinforcing place-based definitions of 'native speaker'. Medgyes, cited above, for example, proposes that native and non-native teachers of English have the same potential to become successful teachers of English, despite what he describes as the non-native speaker's "deficient command of English" (Medgyes, 1992, p. 340). Potentially compensating for their 'deficient' English, non-native teachers, according to Medgyes (1992, pp. 346-347) have the following advantages over native English-speaking teachers: in monolingual classes of students whose language they share, 'non-native' teachers may be able to use this (other) shared language to support learning; the non-native speaker teachers' own "struggle" to learn English may make them more empathetic towards their students' struggle to learn; non-native speaker teachers may be able to anticipate their learners' difficulties with English; non-native speaker teachers may have acquired (meta-)knowledge about how English works from their own study and be able to pass this on to their students; non-native speaker English teachers are may have acquired a range of language learning strategies and be able to pass these on to their students; and the non-native speaker teacher's use of English may provide a more achievable model for their learners. In his defence of the equal value of non-native teachers, Medgyes maintains the two categories, and the implicit judgement of the English of the speakers born in the 'wrong' place as deficient. 
Early work on World Englishes, which recognises the Englishes used in countries other than those traditionally seen as the source of native speakers (the USA, UK, Australia, Canada, Ireland, South Africa, and New Zealand), also uses place-based definitions of speaker-hood. The seminal work of Braj Kachru, for example, which aims to correct an over-emphasis on what he describes $(1992$, p. 3) as 'native speaker' varieties of English, uses countries in his 'concentric circles' model; the 'Inner Circle' comprising "UK, USA, Australia...", i.e. those countries in the list above, the 'Outer Circle' of some ex-colonies of the United Kingdom (such as India, Sri Lanka, Singapore and Malaysia), and the 'Expanding Circle' comprising "Holland, Italy, Japan, Brazil...". The place-based nature of Kachru's model has been critiqued for (amongst other things) its basis in "geography and genetics" by Jenkins (2003, p. 17), who proposes instead a model with a greater focus on who is using English, rather than where they are from (I come back to models of English as a lingua franca in section 3.3 below). An important consequence of Jenkins' emphasis on who not where is her suggestion that 'native' will come to be seen as a pejorative term in multilingual, international contexts (2014, p. 39-40). However, having said that '(non-)native speaker' is starting to be seen as an obsolete term, Jenkins does say that it remains relevant in 'English as a Foreign Language' learning situations, where, "it is self evident that those learning English as a second or subsequent language are not native speakers of the language they are learning" (Jenkins, 2014 p. 38). Even in work that aims to undermine assumptions about birth/place/language, Jenkins is prepared to allow 'native speaker' in educational settings; despite the potential for circular reasoning (they are learning English because they are nonnative speakers = they are non-native speakers because they are learning English).

There is, of course, potential for paradox in scholarly work which uses the term 'native speaker' to argue against the disadvantage associated with being categorised as a 'nonnative speaker': paradox which is compounded by the allowance of 'non-native speaker' to describe learners of English in educational settings (see also Moussu and Llurda, 2008). I argue, however, that what can seem like paradox is in fact a result of the unexamined use of different ontological perspectives on 'English' (for a detailed framework which categorises these various ways of thinking about English, see Hall, this volume). Jenkins' comments, for example, about non-native speakers of English being better international communicators than native speakers, for example, assume an idea of English as a notional resource; in some way connected to place (England) and nationality (English). At the same time, she uses 'English' to mean a social resource; something that accounts for communication between individual users in specific contexts. The claim that non-native speakers can be successful teachers (Medgyes, 1992) is also underpinned by the place/nationality understanding, as well as by an idea of English as a cognitive resource, able to be learnt. As Hall (this volume) argues, different conceptualisations of English are useful for different purposes, in different contexts. Here, I want to emphasise the importance of careful thinking, for TESOL scholars/professionals, about how 'English' is being used and the assumptions that underpin these uses. ...in teacher recruitment

The use of 'native speaker' in teacher recruitment remains current, despite the ongoing efforts of professional organisations to campaign against it. In the UK, for example, the 
British Association of Applied Linguistics (BAAL) has said that their online contact service should avoid distributing " $t$ ] eaching post announcements for 'native' language speakers, as this goes against BAAL's policy on not discriminating between native and nonnative speakers" (BAAL, 2017). Similarly, the US-based professional association, Teachers of English to Speakers of Other Languages (TESOL), has issued a position statement which opposes discrimination against English language teachers on the basis of their 'native language' (TESOL, 2006). Despite these and other efforts, schools operating in, or recruiting from, Inner Circle contexts, as section 2.1 above shows, continue to ask for native speakers and, in many cases, give them preferential treatment (Ali, 2009; Selvi, 2010; Mahboob and Golden, 2013).

These recruitment practices are underpinned by the assumption that the desired outcome of additional language learning is, in all cases, 'native' competence in 'standard English' (see Cunningham, this volume for more on standard English as a target in language learning contexts), and that native speakers have, therefore, an inbuilt advantage as language teachers (for a contrasting view, see Medgyes, above). Conflating English with 'standard English', combined with a belief that learners learn what teachers teach, might seem surprising in the language teaching business (for a convincing account of the usefulness of other languages in the English language learning classroom, for example, see Cook, 1997). It is, however, entirely possible that the kind of recruitment practices our professional organisations campaign against are nothing at all to do with either language or learning. Instead, they may simply be about (literally) selling an identity that is perpetually out of reach, and therefore requires a lifetime of financial commitment. The 'native speaker' identity (as understood in popular discourse) is an identity that cannot, in fact, be achieved, even with unlimited access to resources. Successfully selling the 'means' to an unobtainable goal sounds like an excellent business proposition and, indeed, a fairly recent report shows that the approximately 650,000 students who came to the UK in 2014 to study English (this number does not include 'international' students enrolled at UK universities) added about f1.2 billion to the UK economy (in fees, accommodation and other living costs) and £194 million in tax revenue to the UK government (Chaloner et al, n.d.). While many of those 650,000 students may have enjoyed their experience in the UK, and learned new ways of communicating, none of them will have become 'native speakers' in the sense of the term as it is popularly understood. With this in mind, in section 4 below I suggest ways in which we can continue to actively challenge the use of the phrase in teacher recruitment.

\subsection{Summary}

The use of the idea 'native speaker', in popular discourse, in scholarly work on TESOL, and in teacher recruitment, draws on assumptions about place (this includes place of birth and age of acquisition), competent language use, and the nature of 'English' (as a static, homogeneous and bounded object). In the next section of this chapter, I look at these assumptions in turn.

\section{Contestations of the native speaker idea}

This section begins with a consideration of what could be thought of as 'input' variables, including: place (already mentioned above); the age at which a person starts, and finishes, 
learning a language; and some variables related to task and identity. I also look at the complex and interesting issue of what might be thought of as 'outputs' - competence and proficiency in language use. Finally, I turn to conceptualisations of 'English' and implications of what we think 'English' is for what we think a native speaker of English is.

\section{1 'Input' variables:}

'Nativeness', as we saw above, is often conflated with nationality and/or place. But since national borders are not consistent with linguistic ones, this geography-based native/second/foreign typology is so problematic as to be utterly useless. Age, as an 'input variable' also poses significant problems. Research on age-related factors (such as: the age at which acquisition began; the period of time over which a person has been acquiring; and their level of attainment), can find these factors difficult to separate from each other. This means that the specific effects of age on language processing and ultimate achievement (particularly in the case of additional languages) cannot be independently measured. In addition to the difficulty of separating out within-age variables, there is also the problem of separating age-related effects from the effects of the other variables. This means that, despite neurolinguistic evidence which suggests that the brains of monolingual and multilingual people are different in several ways, we are presently unable to say anything more specific about age-related effects other than that age seems to influence language acquisition and use.

The problem of interacting variables is acknowledged in a review of literature on multilingualism and the brain (Higby et al., 2013), which nevertheless concludes that recent language acquisition research continues to support the critical period hypothesis (CPH). The $\mathrm{CPH}$, first proposed by Lenneberg (1967), claims that there is a limited window during which input must be received and processed before innate mechanisms in the brain change, making subsequent acquisition more difficult. There is some evidence to suggest (Higby et al., 2013) that, although later-learned languages use the 'usual' left-hemisphere language areas of the brain, they also require the use of additional areas to handle the extra work associated with later learning and/or lower levels of attainment. A person who is exposed to English after the end of the critical period, therefore, might process, and use, English in ways that are different from someone who is exposed to English from birth.

From a cognitive perspective, it seems that the age at which a person begins to acquire a language could provide some justification for the two distinct categories of native speaker (exposed to English from birth) and non-native speaker (exposed to English after the critical period), although the evidence for this is by no means clear (see Hall, 2018). Certainly, there are other factors that influence language processing and use. For example, the type of task a language user is engaged in, and their level of competence, also interacts with age in a way that makes it very difficult for researchers to isolate these factors from each other. The level of a speaker's general education may also play a role in language production, as experimental research on the use of complex grammar, in which non-native speakers outperformed native speakers, has shown (Street, 2017).

Equally importantly, while the effects of age on language processing and on attainment can be studied in the laboratory, the interpretation of the results needs to be underpinned by 
an awareness of what 'competence' or 'proficiency' and 'the language' might be taken to mean in different contexts. For example, in this summary of the effects of age on language acquisition, "most bilinguals never attain native-like linguistic competence in the L2 [...] a feat that is especially hard for individuals who begin acquiring the new language after puberty" (Higby et al, 2013, p. 75), the authors assume that a language exists as a stable, definable entity, which is consistently used by the group of people who identify, or who are identified, with these uses. From this perspective, there is only one 'English' for speakers of other languages to learn: a complex series of external facts that can be modelled by textbooks, native speaker teachers, and tests. The learner's job, according to this assumption, is to internalise these facts, and any differences between their use of English and their native speaker teacher's use of English is explained as a cognitive deficit; a failure. According to this view of learning, learners of English as an additional language can only very rarely achieve a successful learning outcome.

Cognitive perspectives on language acquisition and processing provide us with important insights into age- and place-related differences, although the contribution of age to these differences is mediated by other variables such as task type. This alone makes it very problematic for anyone who would claim that age of exposure to English is the basis for categorising a speaker as either 'native' or 'non-native'. In addition to the difficulties caused by these interacting variables, we are faced with the problem of what counts as competent use of a language, as well as what counts as 'the language'. All learners of English, wherever and whenever they are learning, will construct a version of English that is different from that of their teacher's/parent's/peer's version (an 'I-language' in Hall's framework, this volume). The judgement about whether their version is 'native-like' relies on an assumption about what is, and isn't (good) English. These judgements are social and, unless the assumptions about language (use) that underpin them are carefully examined, they run the risk of being wrong.

In an effort to contest over-simplification and more accurately reflect speaker-, and situation-, dependent variation, Leung et al. (1997) have suggested the description of speakers' linguistic repertoires in terms of: expertise (the ability to achieve specific tasks in specific situations); inheritance (the age at which a language in the repertoire began to be used, under what circumstances it was learned); and affiliation (level of comfort in using the language, feelings of belonging to a community of language speakers). This is a welcome recognition of the complex interaction between input variables and variable outputs. Clearly, the term (non-)native speaker generalises about what are extremely heterogeneous groups of language users (Canagarajah, 1999). For example, we know that there is:

- lexico-grammatical and phonological variation within all languages (depending on variables such as age, place, job, hobbies, religion, ethnicity, subculture, and gender);

- no accent-free version of any language;

- variation within the speech and writing of individuals (depending on variables such as their role in a conversation and their relationship with their interlocutor, their languaging purpose, their emotional state, and the social conventions for the context); 
- mixing of languages and varieties for maximum communicative effect by multilingual speakers (Dewaele, 2018, proposes $L 1$ user for monolingual 'native speakers' and $L X$ user for all multilingual users of English).

It is to these output variables that we turn in the next section.

\subsection{Outputs: competence and proficiency}

From the perspective of 'English' as communication ('Englishing', see Hall, this volume), to be a competent user of English requires intelligibility. The same applies for many other judgements of users, such as proficient, good, effective, successful, clear, and so on. There is little agreement, however, about what constitutes intelligibility or about how to measure it (Jenkins, 2000; Derwing and Munro, 2005; Munro et al., 2006). The traditional TESOL position relies on an assumption that intelligibility is the responsibility of $L 2$ learners/users of English. Where intelligibility is judged to be a problem (perhaps because of so-called 'interference' from their first language), TESOL practitioners have assumed the solution to be their students' acquisition of more ('native-like') English.

The world Englishes and English as a lingua franca (ELF) paradigms have challenged the idea of Inner Circle speakers as norm-providers for all learners and users of English, and this has led to a new interest in intelligibility issues for speakers of English as an international language. In this section, I review current research on intelligibility, beginning with work in the ELF paradigm, and contrast this with the world Englishes approach.

Early work on ELF proposed the need for a description and possible codification of the English used by speakers in Kachru's Expanding Circle (for example, China, Greece, Poland, Thailand, etc.). In contrast to a world Englishes approach, ELF scholars were, and are, less interested in national varieties of English and more concerned with describing the English that is used between speakers of different L1s, who are using English as a lingua franca (cf. Part $E$, this volume). For example, using corpus data collected from mainly Expanding, but also Inner and Outer Circle users, Seidlhofer (2004) proposed a list of typical features of the lexicogrammar of ELF users, while Jenkins (2002) documented a similar list for phonology. According to Jenkins (2006, p. 170), Seidlhofer's intention in creating and researching the Vienna-Oxford International Corpus of English (VOICE) of ELF data was to "find out which items are used systematically and frequently, but differently from native speaker use and without causing communication problems, by expert speakers of English from a wide range of [first languages]".

In contrast to this early work in ELF, world Englishes scholars (for example, Smith and Nelson, 1985; Kachru, 2008; Nelson, 2008) have tended to focus on the relative nature of intelligibility rather than on its 'core' features. Smith and Nelson (1985, p. 333), for example, state that "intelligibility is not speaker or listener-centred but is interactional between speaker and hearer", and Nelson notes that "being intelligible means being understood by an interlocutor at a given time in a given situation" (1982, p. 59). This conceptualisation of intelligibility as interactionally accomplished links intelligibility to specific contexts of use, involving factors related to the speaker, the listener, the linguistic and social context, and the environment. 
The co-constructed nature of intelligibility identified by Smith and Nelson has, in fact, long been a feature of the sociolinguistic literature outside the world Englishes paradigm, which has firmly established the context-sensitive, adaptive, idiosyncratic, unpredictable nature of language use (for example, Giles and Powesland, 1975; Gumperz, 1982; Giles et al., 1991). While 'lingua franca' is one possible context, we are not able to predict in advance what purchase this context (as opposed to all the other contexts in simultaneous operation) will have over the actual language use of speakers. Corpus analyses such as those carried out by ELF researchers can obtain traces of consistent use of phonological and lexico-grammatical features by a selected group of speakers who are assumed to have their communicative context in common. But the basis of the selection cannot be shown to account entirely, or even at all, for the traces of regularity, nor can the regularities be assumed to be 'as a result' of the context.

Intelligibility is a contested construction, even within the relatively small subfield of (applied) linguistics represented by the world Englishes and ELF paradigms. What scholars in this subfield are most likely to agree upon, however, is that there is no causal relationship between speaking an Inner Circle (native speaker) variety of English and being intelligible in an international context. Instead, they stress that it is vitally important for all speakers of English (including those in the Inner Circle) to practise adjusting their speech in order to be intelligible to interlocutors from a wide range of language backgrounds. The potential consequences of this position for TESOL are profound, undermining all previous assumptions about users of Inner Circle English as the ideal users and teachers of English. Successful/clear/competent/proficient users of English are, in the words of Canagarajah over a decade ago (see also this volume), "able to monitor each other's language proficiency to determine mutually the appropriate grammar, lexical range and pragmatic conventions that would ensure intelligibility" (2007, pp. 923 - 924).

These monitoring and accommodating strategies may play out in very complex ways. The extent and frequency of use of the strategies can vary within a conversation, shaped by changing awareness of a partner's needs (Hwang et al., 2015); speakers may both converge on and diverge from each other's use of English at different points and in different, perhaps contradictory, ways. Beliefs about group identity (for example 'people like us' versus 'foreigners') has been shown to influence understanding/task achievement (Neuliep, 2013) and prejudicial beliefs about 'other people' can result in a perception of difficulty in understanding them (Hansen and Dovidio, 2016), as well as in perceptions of lower intelligence and competence generally (Au et al., 2017). In other words, in addition to ontologies of the language itself, actual 'successful' uses of English depend partly on a nesting of perceptions about the current task, beliefs about your own and another person's identity, your own and other's relational goals, and the outcome of your interaction (Wang, 2013).

There is, thankfully, some evidence to suggest that TESOL practitioners are less biased in their judgements than those with no experience of teaching English (Huang, 2103; Sheppard et al., 2017), when judging the overall proficiency of a speaker or the content of their language use. And it is also important (including for teachers) to remember that what might be seen as 'unsuccessful' uses of English could provide effective ways of 
demonstrating loyalty to an individual or group associated with such (so-called)

'unsuccessful' uses (Trofimovich and Turuševa, 2015).

Suffice to say that, when it comes to definitions and judgements of a speaker's competence, the picture is very complex and there is no escape from peoples' (including our own) subjective assessments; indeed, we need such judgements in order to formulate a way of speaking to others. But we can, and should, pay attention to how these judgements advantage or disadvantage the people we are speaking to, and attempt to make subsequent adjustments in order to avoid careless, or even deliberate, discrimination. This is a point I return to in Section 4 below.

\subsection{Conceptualisations of 'English'}

In this section, I argue that the question of who is a native speaker is an ontological one (What is 'English'?) and not, as it is often presented, a matter of age or place of acquisition (see above). The practice of dividing up speakers into the two mutually exclusive categories of 'native' and 'non-native' requires a belief in 'English' as a monolithic object, with clear borders between users of 'native speaker English' and users of 'non-native speaker English' There are similar issues with the division of speakers into the two groups 'learners' and users', given that all users are also (to some extent) learners, and all learners are users (Firth and Wagner, 1997; Canagarajah, 2007).

An important element of monolithic approaches to language is a focus on a core, or 'standard', against which other varieties are judged. The belief in a standard form of English is a very popular one, even though so-called 'standard' varieties of English are inevitably social rather than cognitive entities (Hopper, 1998; Hall, 2005, 2018; Cunningham, this volume). In fact, all individual speakers have their own ultimately unique linguistic repertoires ('I-languages'). Groups of speakers do share different degrees of awareness of a set of conventions about acceptable, prestigious, and desirable sounds, words, and syntax in specific situations ('N-language'), but again, these are beliefs rather than actually/exactly the same set of linguistic resources, deployed in consistent, entirely predictable ways.

We have argued elsewhere that monolithic conceptualisations of English are not true, fair, helpful, or sustainable (Hall and Wicaksono, 2013). Despite this, such ways of thinking about language continue to underpin the use of 'native' or 'non-native' to categorise speakers of English, with both benefits and drawbacks for individuals and groups of English language users.

\subsection{Summary}

In this section, I began by thinking about the concept of 'place' and the interaction with another input variable, 'age'. I showed how the framing of these concepts as having a predictable impact on 'competent' language use is challenged by the complex and difficult problem of defining 'competence'. I ended the section with the question of what counts as 'English', a question that has profound implications for the TESOL profession and for debates about 'nativeness'. In the final section of this chapter I consider what might be done to take account of these contestations of the idea of a native speaker, the 
potential danger of the concept for members of the TESOL profession, as well at its use, in certain cases, to justify the operations of some of its educational institutions.

4 What action can we take against the use of 'native speaker' in English language teaching?

Given our conclusions above, it is clearly essential for TESOL professionals/scholars to think very carefully about how the categories of native and non-native speaker emerge through a discursive process, a process which Aneja (2016) refers to as, "(non)native speakering".

Accepting that these categories are discursively constructed, and not 'natural', forces us to notice the complexity of, variation within, and fluidity between, the categories. It is the first step towards taking action against the unexamined use of the categories. Thinking carefully about our naming practices and of the rights of members of groups to identify themselves (and to change their mind, and to disagree with each other about the name of their group) is not just so-called 'political correctness'. It is an important (and easy!) way to avoid thoughtless and damaging generalisations and is, therefore, an essential first step in avoiding discrimination (for more about labelling/naming practices, see Hall et al., 2017, pp. 52-57).

In addition, we need to raise awareness about what 'English' is, and consider the implications of definitions of 'competence' for teaching and testing (see Part D, this volume). There are implications too for teacher training and recruitment, some of which are considered below.

\subsection{Raising awareness about what language is}

Organisations that represent the TESOL profession have already recognised (over a decade ago...) the importance of challenging monolithic conceptualisations of language that privilege the idea of a 'standard' above other uses. The TESOL International Association, for example, "encourages the recognition and appreciation of all varieties of English, including dialects, creoles, and world Englishes. In terms of language teaching, TESOL does not advocate one standard or variety of English over another. Rather, TESOL urges English language teachers to make informed decisions at local, regional, and/or national levels, taking into account the purposes and contexts of use that are most relevant to their learners" (TESOL, 2008).

For this goal to be achieved, however, there continues to be a need for awareness-raising tasks that are accessible to teachers. The online, free-of-charge course Changing Englishes (Hall and Wicaksono, 2013) is an example of this kind of resource, but more, and more locally-relevant, resources are still needed. The design, publication and use of such resources would be a valuable contribution towards efforts to challenge the untrue, unfair, unjust, and unsustainable monolithic conceptualisations of English and related ideas about (non-)native speakers.

\subsection{Raising awareness about the implications of definitions of 'competence'}

It has been suggested that what gets taught and tested in language classrooms has little effect on how English is actually used outside of the educational environment, despite 
(all?) our government's attempts to regulate what kind of English is taught in schools (Anderson, 2017; Goodwyn, this volume; Goddard, this volume). It is possible, however, that tasks which encourage students to consider the context in which they are using English, the beliefs about appropriacy that are embedded in that context, and how successful communicative outcomes might be defined and measured, would be useful. Training students to notice the effects of their language use on others, and on task achievement, could be part of a series of such tasks (see Wicaksono, 2013, for an example). More research is needed into this interesting and important issue, as is more sharing of relevant classroom resources.

The challenges to monolithic thinking about what 'English' is also have serious implications for testing. Hall (2014, p. 383) argues for a 'plurilithic' (i.e. not a monolithic) perspective, claiming: "Recognition of the plurilithic reality of English necessitates a radical rethinking of the nature and purpose of English testing. Consistent with a plurilithic perspective would be the assessment of a learner's Englishing: what they do with the language in specific situations [...] [W] hat should be assessed (where possible and appropriate) is learners' performance on communicative tasks in English that are appropriate to their own goals and contexts, rather than their knowledge and use of 'English itself'". Such a perspective could mean using a range of varieties of English to test for understanding and reward for the use of the kind of accommodation/task achievement strategies mentioned above.

\subsection{Raising awareness about implications for teacher training and recruitment}

In a study of trainees from around the world on the Cambridge ESOL Certificate in English Language teaching to Adults and the Trinity College London CertESOL, Anderson (2016, p. 271) concludes, "current initial teacher training courses are not well suited to the needs of NNS participants, who may require a very different type of course to NS participants". I would argue even more strongly that such courses urgently require an updated approach to language for all trainees, equipping them to challenge the untrue and unjust beliefs about language that underpin discriminatory hiring practices in their profession.

Once again, professional organisations provide advocacy on this issue: "The use of the labels 'native speaker' and 'nonnative speaker' in hiring criteria is misleading, as this labelling minimizes the formal education, linguistic expertise, teaching experience, and professional preparation of teachers. All educators should be evaluated within the same criteria. Nonnative English-speaking educators should not be singled out because of their native language" (TESOL, 2006). At my own institution, conversations with our Careers service have led to a policy that requires members of the team to contact schools who send through advertisements that use the term 'native speaker' and ask them about their rationale for the term. This is a new effort (based on an idea proposed by Kamhi-Stein, 2016) and we are yet to see what the impact of our decision might be.

\section{Conclusion}

This chapter has explored the idea of a '(non-)native' speaker of English, in the context of teaching English to speakers of other languages (TESOL). Despite much scholarly and professional argument against the term, the use of '(non-)native' speaker to describe 
a person's use of English remains common in a variety of domains. This is due to a lack of understanding of how and where English is used, a general confusion about what we mean by 'English', and, perhaps, a deliberate undermining of the rights of large groups of users to think of themselves as competent (and therefore deserving of higher pay-in the case of teachers-or not requiring further classroom instruction - in the case of learners).

Contestations from the point of view of ontologies of English, language cognition, English as a lingua franca, and identities add up to a strong case for abandoning the (non-)native speaker of English idea. Not just because there is no evidence for any kind of definable 'nativeness', but also because there is still a lot more work for scholars and language teachers to do on what 'English' means. In the meantime, we are all language users of varying degrees of (localised) success, depending on the definition and measurement of 'success'. The relevance of whether or not our language is considered 'English' to the achievement of a communicative task is limited and the unthinking (or cynical) use of the native speaker idea is potentially damaging. I propose that language teachers should focus on 'Englishing', rather than on teach their students 'English'. This would require working in collaboration with students to identify specific tasks, work out how they (and others) might judge their successful achievement of these tasks, and then locating and acquiring the resources they need for successful task achievement.

As we learn more about language and 'languages', the (arbitrary) naming of languages and problematic assumptions about who is (dis)counted as a 'speaker', should become less interesting and relevant. We can contribute towards the contestation of arbitrary names and problematic assumptions by asking 'what is English', as well as 'what is needed to communicate here/now?' The answer to both questions might be that nobody agrees, but at least in the ensuing discussion our competing assumptions will be made visible.

\section{References}

Anderson, J. (2016). Initial teacher training courses and non-native speaker teachers, ELT Journal, 70(3), 261-74.

Anderson, J. (2018). Reimagining English language learners from a translingual perspective. ELT Journal, 72(1), 247-249.

Aneja, G. A. (2016). Rethinking nativeness: Toward a dynamic paradigm of (non)native speakering, Critical Inquiry in Language Studies, 13(4), 351-379.

Aneja, G. A. (2016). (Non)native speakered: Rethinking (non)nativeness and teacher identity in TESOL teacher education', TESOL Quarterly, 50(3), 572-597.

Au, T., Kwok, A., Tong, L., Cheng, L., Tse, H. and Jun, S. (2017). The social costs in communication hiccups between native and nonnative speakers, Journal of CrossCultural Psychology, 48(3), 369-383.

British Association of Applied Linguistics (BAAL), BAALmail: https://baalweb.wordpress.com/baalmail/

Canagarajah, S. (2007). Lingua Franca English, multilingual communities, and language acquisition. The Modern Language Journal, 91, 923-39.

Chaloner, J., Evans, A. and Pragnell, M. (no date). Supporting the British economy through teaching English as a foreign language: An assessment of the contribution of 
English language teaching to the United Kingdom economy. English UK:

https://www.englishuk.com/uploads/assets/members/newsflash/2015/11_nov/Econo mic_impact_report_44pp_WEB.pdf

Cook, V. (1999). Going beyond the native speaker in language teaching, TESOL Quarterly, 33(2), 185-209.

Dewaele, J. (2018). Why the dichotomy 'L1 Versus LX User' is better than 'Native Versus Non-native Speaker', Applied Linguistics, 39(2), 236-240.

Dings, A. (2012). Native speaker/Nonnative speaker interaction and orientation to novice/expert identity, Journal of Pragmatics: An Interdisciplinary Journal of Language Studies, 44(11), 1503-18.

Firth, A. and Wagner, J. (1997). On discourse, communication, and (some) fundamental concepts in SLA research. The Modern Language Journal, 81, 285-300.

Hansen, K. and Dovidio, J. (2016). Social dominance orientation, nonnative accents, and hiring recommendations, Cultural Diversity and Ethnic Minority Psychology, 22(4), 544551.

Hall, C. J. (2005). An introduction to language and linguistics. Breaking the language spell. London: Continuum.

Hall, C. J. (2014). Moving beyond accuracy: From tests of English to tests of 'Englishing'. ELT Journal, 68(4), 376-85.

Hall, C. J. (2018). Cognitive perspectives on English as a Lingua Franca. In Jenkins, J., Baker, W. and Dewey, M. (eds). Routledge handbook of English as a Lingua Franca (pp. 74-84). London: Routledge.

Hall, C. J. and Wicaksono, R. (2013). Changing Englishes: An interactive course for teachers. Online. Available at www.yorksj.ac.uk/changing-englishes.

Hall, C. J., Wicaksono, R., Liu, S., Qian, Y. and Xu, X. (2017). Exploring teachers' ontologies of English: Monolithic conceptions of grammar in a group of Chinese teachers. International Journal of Applied Linguistics, (27)1, 87-109.

Harvey, E., ed. (1480/1984). The Court of Sapience. University of Toronto Press.

Higby, E., Kim, J. and Obler, L. K. (2013). Multilingualism and the brain. Annual Review of Applied Linguistics, 33, 68-101.

Huang, B. H. (2013). The effects of accent familiarity and language teaching experience on raters' judgments of non-native speech, System, 41, 770-85.

Hwang, J., Brennan, S. and Huffman, M. (2015). Phonetic adaptation in non-native spoken dialogue: Effects of priming and audience design, Journal of Memory and Language, 81, 72-90.

Kachru, B., ed. (1982). The Other Tongue -- English Across Cultures. Urbana, Ill.: University of Illinois Press.

Kachru, B., ed. (1992). (second edition) The Other Tongue -- English Across Cultures. Urbana, III.: University of Illinois Press.

Kamhi-Stein, L.D. (2016). The non-native English speaker teachers in TESOL movement, ELT Journal, 70(2), 180-189.

Lenneberg, E. H. (1967). Biological foundations of language. New York: Wiley.

Medgyes, P. (1992). Native or non-native: who's worth more? ELT Journal, 46(4), 340-49.

Morrison, L. (2016), Native English speakers are the world's worst communicators. http://www.bbc.com/capital/story/20161028-native-english-speakers-are-the-worldsworst-communicators 
Moussu, L. and Llurda, E. (2008). Non-native English speaking English language teachers: history and research. Language Teaching, 41(3), 315-48.

Neuliep, J. and Speten-Hansen, K. (2013). The influence of ethnocentrism on social perceptions of nonnative accents, Language and Communication, 33, 167-176.

Rampton, M. B. H. (1990). Displacing the 'native speaker': expertise, affiliation, and inheritance. ELT Journal, 44(2), 97-101.

Rosetta Stone (n.d.) British English Online Language Tutor http://jobs.jobvite.com/rosettastone/job/oamB7fwY?sType=Indeedandutm_source=In deedandutm_medium=organicandutm_campaign=Indeed

Pae, T. (2017). Effects of the differences between native and non-native English-speaking teachers on students' attitudes and motivation toward learning English, Asia Pacific Journal of Education, 37(2), 163-178.

Russo, M., Islam, G. and Koyuncu, B. (2017). Non-native accents and stigma: How selffulfilling prophesies can affect career outcomes, Human Resource Management Review, 27, 507-520.

Sheppard, B., Elliott, N. and Baese-Berk, M. (2017). Comprehensibility and intelligibility of international student speech: Comparing perceptions of university EAP instructors and content faculty, Journal of English for Academic Purposes, 26, 42-51.

Street, J. A. (2017). This is the native speaker that the non-native speaker outperformed: Individual, education-related differences in the processing and interpretation of Object Relative Clauses by native and non-native speakers of English, Language Sciences, 59, 192-203.

Taylor, R. and Zanini, N (2017). Native speakers in A level modern foreign languages. OFQUAL. https://www.gov.uk/government/publications/native-speakers-in-a-levelmodern-foreign-languages

TESOL, (2006). Position Statement Against Discrimination of Nonnative Speakers of English in the Field of TESOL. https://www.tesol.org/docs/default-source/advocacy/positionstatement-against-nnest-discrimination-march-2006.pdf?sfvrsn=2

TESOL, (2008). Position Statement on English as a Global Language. http://www.tesol.org/docs/pdf/10884.pdf?sfvrsn=2

Trofimovich, P. and Turuševa, L. (2015). Ethnic identity and second language learning, Annual Review of Applied Linguistics, 35, 234-52.

Wang, Z., Arndt, A. D., Singh, S. N., Biernat, M. and Liu, F. (2013). "You Lost Me at Hello": How and when accent-based biases are expressed and suppressed. International Journal of Research in Marketing, 30(4), 185-196.

Wicaksono, R. (2013). Raising students' awareness of the construction of communicative (in)competence in international classrooms. In J. Ryan (ed.) Cross cultural teaching and learning for home and international students: Internationalisation of pedagogy and curriculum in Higher Education. London and New York: Routledge. 